\title{
Cooperation and Competition: The Analysis of Strategy in Duopoly Online Video Websites
}

\author{
Li Zhihong, Cheng Yu, Wu Yushan \\ School of Business Administration, South China University of Technology, Guangzhou, China
}

Email address:

cheng.yu@mail.scut.edu.cn (Cheng Yu)

To cite this article:

Li Zhihong, Cheng Yu, Wu Yushan. Cooperation and Competition: The Analysis of Strategy in Duopoly Online Video Websites. Science Journal of Business and Management. Vol. 3, No. 4, 2015, pp. 109-115. doi: 10.11648/j.sjbm.20150304.13

\begin{abstract}
This paper studies the coopetition between two websites which are platforms to offer online video. We use two-sided market theory and game theory to analyze a duopoly market of online video websites. An online video service system is established, including online video websites, copyright owners of online video, advertisers and viewers. After discussing the negotiation of copyright trading, the effect for viewers to watch online video, the effect of advertising, we focus on the coopetition between the duopoly online video websites. We conclude that cooperation is the optimal strategy to promote the development of online video websites.
\end{abstract}

Keywords: Online Video Service, Online Video Website, Coopetition, Game Theory, Two-Sided Market

\section{Introduction}

Since 2005 the world's largest video site Youtube has been established, the video site has always been drawing high attention of the Internet community in China and other countries. And the online video service has become an important way of entertainment for online users. Nowadays, Youtube, Hulu, Netflix and other video sites are growing fast, meanwhile Youku, Tudou, iQIYI, other video sites in China are also becoming more and more popular. Moreover, the competition among these video sites is stiff.

The data released by IResearch shows that in May 2012, Chinese online video users accounted for 96\%, and the amount of users was firstly larger than that of search engine. Then online video service became the first major Internet applications. Online video service is a huge rapidly growing market, on which the competition is becoming more and more compelling. So far, the industry and services on video sites catch people's high attention, but academic research don't. Currently, similar studies mainly focus on traditional television, radio, magazines and other traditional media.

Analyzing the industry features, the video site has the typical characteristics of a "two-sided markets". Back in 2003, the two-sided market theory, advanced by Rochet and Tirole[1] and Caillaud and Jullien[2], has become an important theory on the research of pricing and income distribution problem for platform enterprises. Armstrong[3] defined the two-sided market as a trading market where two users make a deal through its trading platform, and the interests of one side depends on the another's scale and quality. According to the definition of the two-sided market from Armstrong, online video service is a typical two-sided market. Video site is a platform and content provider for online video service, whose user communities are including video users and advertisers. Video users benefit from watching videos on video sites, and advertisers can attract more new consumers through advertising on video sites and then gain more revenue.

Reisinger[4] used the two-sided market theory to build a model about the competition between users and advertisers in the media market. Anderson and Coate[5] first studied the competition model in television channels, analyzing the relationship between the TV programs provided by two channels and the quantity of the ads. Considering in a competing media platform where users watch videos in payment or in free, Peitz and Valletti[6] analyzed the difference of charging and free mode in advertising intensity, television content, and social welfare on media platform. Prasad et al[7] studied pricing policy of e-media advertising provider and user fee policies under the circumstances of oligopoly. Choi[8] constructed a free competition model of the broadcast industry, considering both free and subscription operating system. Kaiser and Song[9] used empirical method to analyze users' disgust for magazine ads in different situations.

Kind et al[10] set oligopoly game model to analyze 
audience's disgust with television advertising. Häckner and Nyberg[11] made duopoly game model to analyze the utility of ads in media market and its influence on consumers. Crampes et al[12] considered the case of charging to advertisers and users both in media platforms, and searched for the game equilibrium value of the two competing platforms. Gabszewicz et al[13] analyzed the competition of TV program and advertising strategies between two different channels. Bengtsson and Kock[14] studied the competition and cooperation relationship between different enterprises and believed that cooperation contribute to promoting the integration of enterprise resource and ability, so as to increase enterprise's competitiveness. In this paper, the results of competition and cooperation between video sites consistent with Bengtsson and Kock's study.

This paper is based on the two-sided market theory to analyze the online video service. Using game theory, we make duopoly model and related assumptions, and then comprehensively analyze the online video service system consisting of video sites, video copyright providers, advertisers and video users. To explore the optimal strategy of online video services' development, we focus on researching the competition and cooperation relationship between different video sites.

\section{Model and Assumptions}

We assume that the online video service system consists of 4 elements, video sites, video copyright agent, advertisers and video users, as seen Figure 1. In this system, the video sites are platforms for online video service, and they have to acquire the copyright to play video from the copyright agent. Then the copyright agent gain profit by selling the right to video sites. The video site's revenue comes from advertisers' payment for advertising on their site, and we assume it is the only revenue source for the video site. Users watch videos for free on selected sites according to their own preferences and differences of the two sites. The assumption of watching online video for free agrees with the realistic situation of website's development. Currently online video service is still in its infancy, and most video sites for video users take a free strategy, namely unilateral pricing strategy for advertisers. Assuming the online video service market is a duopoly market, online video services are provided by only two video sites, which have competition or cooperation relationship.

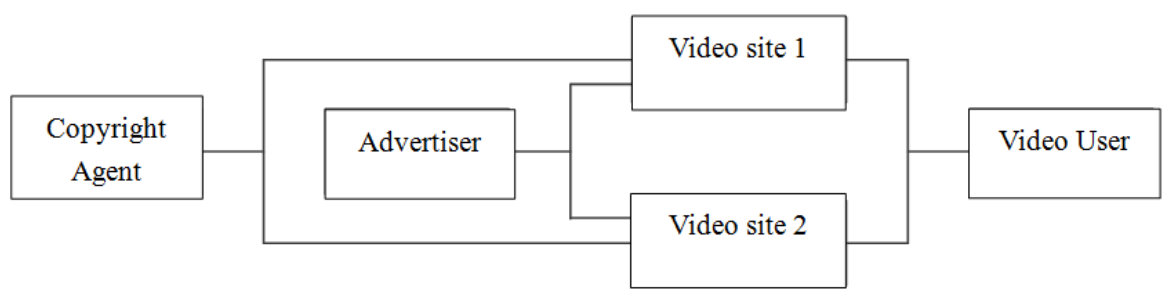

Fig. 1. Elements of Online Video Service System.

Considering that most copyrighted videos are not made only to play on the video site, for example, the film is made to be released in the cinema, and the TV series is produced in order to play on television. Therefore, we assume that the production costs of copyrighted video have been recovered through other channels. This assumption tells us the cost that copyright agent spend on selling copyright to video sites is zero. Assume the profit function of copyright agent selling the video content copyright is:

$$
\begin{aligned}
& \Pi_{\mathrm{h}}=\mathrm{P} \\
& \text { s.t. } \quad \mathrm{P} \geq \mathrm{P}_{0}
\end{aligned}
$$

Where $\mathrm{P}$ is the price when the copyright agent sells the video copyright to the video sites; $P_{0}$ is the reservation price for the sale of the video copyright.

Assume $v_{i}$ is the value of video content assessed by the video site, and $P_{i}$ is the bid for purchasing the video copyright. When copyright agent negotiates an agreement on copyright, the two video sites can compete with each other to achieve copyright exclusivity, or cooperate and share the video copyright.

Considering the utility of users when watching video online, this paper refers to the model used by Haaland and Kind [15] which, from the perspective of international economics, construct the utility function when consumers from two different companies buy the same product. For a universal user, we assume his/her utility function of watching the videos in two different video sites is:

$$
\mathrm{U}=\mathrm{q}_{1}+\mathrm{q}_{2}-\frac{1}{2}\left(\mathrm{q}_{1}^{2}+\mathrm{q}_{2}^{2}+\theta \mathrm{q}_{1} \mathrm{q}_{2}\right)
$$

Where $q_{i}$ is the user demand for video on the video site $i$, $\theta(0 \leq \theta \leq 1)$ is the differences of user experience between two different sites. We define $\mathrm{q}=q_{1}+q_{2}$ as the total user demand for video on the two sites. The bigger $\theta$ is, the more it costs when user changing a video site to another.

Within the considered time, the net surplus of users' watching video in two sites is:

$$
\mathrm{CS}=\mathrm{U}-\alpha\left(\mathrm{a}_{1} \mathrm{q}_{1}+\mathrm{a}_{2} \mathrm{q}_{2}\right)
$$

Where $\alpha$ is the intensity coefficient which denotes the users' disutility of advertisement. $a_{i}$ is the quantity of ads that users watch on the video site. Suppose the user is advertising aversion, $\alpha \mathrm{a}_{\mathrm{i}} \mathrm{q}_{\mathrm{i}}$ is the sum of advertising disutility. We define $a=a_{1}+a_{2}$ as the total quantity of ads that users watched. 
As $\frac{\partial \mathrm{CS}}{\partial \theta}=-\frac{1}{2} \mathrm{q}_{1} \mathrm{q}_{2} \leq 0, \mathrm{CS}$ is negatively correlated to $\theta$, that is , the net surplus of users' watching video in two sites is negatively correlated to the differences of user experience between them. $\theta$ increases the cost of user turning to another site, and the cost decreases the utility of watching video on two sites.

From the first order conditions on $\operatorname{CS}\left(\mathrm{q}_{1}, \mathrm{q}_{2}\right)$, it can be obtained on the user demand on the two different video sites are:

$$
\begin{aligned}
& \mathrm{q}_{1}=\frac{2\left(2-\theta-2 \alpha \mathrm{a}_{1}+\theta \alpha \mathrm{a}_{2}\right)}{4-\theta^{2}} \\
& \mathrm{q}_{2}=\frac{2\left(2-\theta-2 \alpha \mathrm{a}_{2}+\theta \alpha \mathrm{a}_{1}\right)}{4-\theta^{2}}
\end{aligned}
$$

Then the total demand is:

$$
\mathrm{q}=\frac{2(2-\alpha \mathrm{a})}{2+\theta}
$$

From $\frac{\partial q}{\partial a}=-\frac{2 \alpha}{2+\theta}<0$, we can see that the total demand of online video increases as the amount of ads decreases. $\frac{\partial \mathrm{q}}{\partial \alpha}=-\frac{2 \mathrm{a}}{2+\theta}<0$, so the total demand of online video increases as the intensity coefficient of advertising disutility decreases.

Suppose $p_{i}$ is the price of the video site $i$ for advertising, then the revenue of the video site $i$ is

$$
\mathrm{R}_{\mathrm{i}}=\mathrm{a}_{\mathrm{i}} \mathrm{p}_{\mathrm{i}}
$$

We define $R=R_{1}+R_{2}$ as the total revenue for the video site $\mathrm{i}$ and $\mathrm{j}$. Considering all advertisers as a whole and advertising on the site $\mathrm{i}$, the profit function as follows:

$$
\Pi_{\mathrm{ai}}=\beta \mathrm{a}_{\mathrm{i}} \mathrm{q}_{\mathrm{i}}-\mathrm{a}_{\mathrm{i}} \mathrm{p}_{\mathrm{i}}
$$

Where $\beta$ is the intensity coefficient of utility advertisers acquired from advertising on the video site. $\beta a_{i} q_{i}$ is the revenue achieved by adverting on the video site $i$. And $a_{i} p_{i}$ is the adverting cost on the site.

The total profit function of adverting on two video sites is:

$$
\Pi_{\mathrm{a}}=\Pi_{\mathrm{a} 1}+\Pi_{\mathrm{a} 2}=\beta\left(\mathrm{a}_{1} \mathrm{q}_{1}+\mathrm{a}_{2} \mathrm{q}_{2}\right)-\left(\mathrm{p}_{1} \mathrm{a}_{1}+\mathrm{p}_{2} \mathrm{a}_{2}\right)
$$

Substituting (4) and (5) into (8), and according to the first-order conditions we got the amount of ads on two different video sites:

$$
\begin{aligned}
& a_{1}=\frac{2 \beta-2 p_{1}-\theta p_{2}}{4 \beta \alpha} \\
& a_{2}=\frac{2 \beta-2 p_{2}-\theta p_{1}}{4 \beta \alpha}
\end{aligned}
$$

Substituting (10) and (11) into (7), we get each site's avenue:

$$
\begin{aligned}
\mathrm{R}_{1} & =\frac{\left(2 \beta-2 \mathrm{p}_{1}-\theta \mathrm{p}_{2}\right) \mathrm{p}_{1}}{4 \alpha \beta} \\
\mathrm{R}_{2} & =\frac{\left(2 \beta-2 \mathrm{p}_{2}-\theta \mathrm{p}_{1}\right) \mathrm{p}_{2}}{4 \alpha \beta}
\end{aligned}
$$

Then the total revenue for the two video sites is:

$$
\mathrm{R}=\frac{\left(2 \beta-2 \mathrm{p}_{1}-\theta \mathrm{p}_{2}\right) \mathrm{p}_{1}+\left(2 \beta-2 \mathrm{p}_{2}-\theta \mathrm{p}_{1}\right) \mathrm{p}_{2}}{4 \alpha \beta}
$$

\section{Copyright Copetetion and Cooperation}

When copyright agent provides videos to the video sites, the agent can gain not only royalty income directly, but also other positive utility, for instance, expanding market share, enhancing visibility. Therefore, Considering from the perspective of strategic development, copyright agents have their willingness to sell the copyright of online video to the video site.

Suppose the online copyright is a one-time sale, that is, copyright agent is not allowed to sell an online copyright which has been sold to a site to another site. But two video sites can work together, making an alliance to purchase the copyright collectively.

If the two video sites compete with each other, the conditions for the success of video copyright trading are

$$
\max \left\{P_{1}, P_{2}\right\} \geq P_{0} \text { and } P_{1} \leq v_{1}, P_{2} \leq v_{2} .
$$

As the two sites biding, the higher one can get the sole copyright to play online video, so the final transaction price is $\mathrm{P}=\max \left\{\min \left\{v_{1}, v_{2}\right\}, P_{0}\right\}$.

If the two video sites decide to cooperate, the conditions for the success of video copyright trading are

$$
\max \left\{P_{1}+P_{2}\right\} \geq P_{0} \text { and } \max \left\{P_{1}+P_{2}\right\} \leq v_{1}+v_{2} \text {. }
$$

As the two sites allying, they share the online video copyright, so the final transaction price is $\mathrm{P}=\mathrm{P}_{0}$.

Pro. 1 When the two video sites negotiate with the copyright agent on copyright trading, cooperation is more advantageous to facilitate completion of the transaction than competition.

We know that the constraint condition for copyright trading in competition are $\max \left\{P_{1}, P_{2}\right\} \geq P_{0}$ and $P_{1} \leq v_{1}, P_{2} \leq v_{2}$, while $\max \left\{P_{1}+P_{2}\right\} \geq P_{0}$ and $\max \left\{P_{1}+P_{2}\right\} \leq v_{1}+v_{2}$ in cooperation. It is obvious that the constraint in cooperation is stronger than that in competition, which means the cooperation is more advantageous to facilitate completion of the transaction than competition.

Pro. 2 When the two video sites negotiate with the copyright agent on copyright trading, cooperation between the two sites is more advantageous to reduce the purchase cost than competition.

Discussed above, the competing copyright price is 
$\max \left\{\min \left\{v_{1}, v_{2}\right\}, P_{0}\right\}$ while cooperating price is $P_{0}$. Obviously, the latter is lower.

About Pro. 2 , it can be proved from the video copyright trading in Shanghai TV Festival - "International Film Trade Show", June 2012. In that trade, there have been five major Chinese video sites jointly buy video copyright, not in the old way of that a video site buys the copyright at a high price. The new trading way resulted in decreasing the copyright price by more than half, compared with the old way. Moreover, since each video site gives a lot of publicity and promotion to the video they bought, the cooperation mode that video sites jointly purchase the copyright is beneficial to the video content's transmission on the Internet. Therefore, cooperation meets the interests of the copyright agent. It follows that, owing to the joint purchasing copyright, the sale and purchase of video copyright become sensible and online video services market is developing in a healthy way.

\section{Demonstration and Results}

According to the analysis above, when the two video sites negotiate with the copyright agent on copyright trading, the cooperation of purchasing the copyright jointly is the optimal decision in the interests of both sides. In the operation of two video sites, there also exists the game of competition and cooperation, the advertising pricing. We are going to this optimal decision in the operational process below.

\subsection{Competition}

If two sites decide to compete with each other, we use Stackelberg game model to analyze their own decision. Stackelberg game, proposed by economists Stackberg, is the classical decision theory that two participants have different decision-making positions in duopoly market. Assuming that the video site 1 is a leader and the site 2 is a follower, they determine each other's price in competition.

First, consider the follow's price decision:

$$
\begin{aligned}
& \operatorname{Max} \quad \mathrm{R}_{2}=\frac{\left(2 \beta-2 \mathrm{p}_{2}-\theta \mathrm{p}_{1}\right) \mathrm{p}_{2}}{4 \alpha \beta} \\
& \text { s.t. } \quad \mathrm{p}_{1}>0, \mathrm{p}_{2}>0 .
\end{aligned}
$$

According to first order condition, we get the follow's price-response curve:

$$
\mathrm{p}_{2}=\frac{1}{2} \beta-\frac{1}{4} \theta \mathrm{p}_{1}
$$

Then, consider the leader's price decision:

$$
\begin{gathered}
\operatorname{Max} R_{1}=\frac{\left(2 \beta-2 p_{1}-\theta p_{2}\right) p_{1}}{4 \alpha \beta} \\
\text { s.t. } p_{1}>0, p_{2}>0
\end{gathered}
$$

Put (16) into (17). According to first order condition, we get the optimal advertising price of the site 1 :

$$
\mathrm{p}_{1}^{*}=\frac{\beta(4-\theta)}{8-\theta^{2}}
$$

So the optimal price of the site 2 is:

$$
\mathrm{p}_{2}{ }^{*}=\frac{\beta\left(16-4 \theta-\theta^{2}\right)}{4\left(8-\theta^{2}\right)}
$$

We can see the related results of Stackelber Model on table1.

Table 1. Results of Stackelberg Model in Competition.

\begin{tabular}{lll}
\hline & Video Site 1 & Video Site 2 \\
\hline Advertising Price & $\mathrm{p}_{1}{ }^{*}=\frac{\beta(4-\theta)}{8-\theta^{2}}$ & $\mathrm{p}_{2}{ }^{*}=\frac{\beta\left(16-4 \theta-\theta^{2}\right)}{4\left(8-\theta^{2}\right)}$ \\
Advertising Quantity & $\mathrm{a}_{1}{ }^{*}=\frac{4-\theta}{16 \alpha}$ & $\mathrm{a}_{2}{ }^{*}=\frac{16-4 \theta-\theta^{2}}{8 \alpha\left(8-\theta^{2}\right)}$ \\
Advertiser's Return & $\Pi_{\mathrm{a} 1}{ }^{*}=\frac{\beta(4-\theta)\left(8-2 \theta-\theta^{2}\right)}{32 \alpha(2+\theta)\left(8-\theta^{2}\right)}$ & $\Pi_{\mathrm{a} 2}{ }^{*}=\frac{\beta\left(16-4 \theta-\theta^{2}\right)\left(32-8 \theta-2 \theta^{2}+\theta^{3}\right)}{64 \alpha(2+\theta)\left(8-\theta^{2}\right)^{2}}$ \\
User Demand & $\mathrm{q}_{1}{ }^{*}=\frac{24+2 \theta-3 \theta^{2}}{2(2+\theta)\left(8-\theta^{2}\right)}$ & $\mathrm{q}_{2}{ }^{*}=\frac{96+8 \theta-14 \theta^{2}-\theta^{3}}{8(2+\theta)\left(8-\theta^{2}\right)}$ \\
Website Income & $\mathrm{R}_{1}{ }^{*}=\frac{\beta(4-\theta)^{2}}{16 \alpha\left(8-\theta^{2}\right)}$ & $\mathrm{R}_{2}{ }^{*}=\frac{\beta\left(16-4 \theta-\theta^{2}\right)^{2}}{32 \alpha\left(8-\theta^{2}\right)}$ \\
\hline
\end{tabular}

\subsection{Cooperation}

If two sites decide to cooperate and make an alliance, it aims to maximize the alliance's total return. When the video site 1 and 2 adopt a cooperative game, they make the adverting price to maximize total revenue. That is:

$$
\begin{array}{ll}
\operatorname{Max} & \mathrm{R}=\frac{\left(2 \beta-2 \mathrm{p}_{1}-\theta \mathrm{p}_{2}\right) \mathrm{p}_{1}+\left(2 \beta-2 \mathrm{p}_{2}-\theta \mathrm{p}_{1}\right) \mathrm{p}_{2}}{4 \alpha \beta} \\
\text { s.t. } & \mathrm{p}_{1}>0, \mathrm{p}_{2}>0
\end{array}
$$

According to the first order conditions, the optimal advertising price of site 1 is $\mathrm{p}_{1}{ }^{*}=\frac{\beta}{2+\theta}$, while the optimal 
price of site 2 is $\mathrm{p}_{2}{ }^{*}=\frac{\beta}{2+\theta}$. The related results of cooperation are seen in table 2 .

Table 2. Results of Cooperation.

\begin{tabular}{lll}
\hline & Video 1 & Video 2 \\
\hline Advertising Price & $\mathrm{p}_{1}{ }^{*}=\frac{\beta}{2+\theta}$ & $\mathrm{p}_{2}{ }^{*}=\frac{\beta}{2+\theta}$ \\
Advertising Quantity & $\mathrm{a}_{1}{ }^{*}=\frac{1}{4 \alpha}$ & $\mathrm{a}_{2}{ }^{*}=\frac{1}{4 \alpha}$ \\
Advertiser's Return & $\Pi_{\mathrm{a} 1}{ }^{*}=\frac{\beta}{8 \alpha(2+\theta)}$ & $\Pi_{\mathrm{a} 2}{ }^{*}=\frac{\beta}{8 \alpha(2+\theta)}$ \\
User Demand & $\mathrm{q}_{1}{ }^{*}=\frac{3}{2(2+\theta)}$ & $\mathrm{q}_{2}{ }^{*}=\frac{3}{2(2+\theta)}$ \\
Website Income & $\mathrm{R}_{1}{ }^{*}=\frac{\beta}{4 \alpha(2+\theta)}$ & $\mathrm{R}_{2}{ }^{*}=\frac{\beta}{4 \alpha(2+\theta)}$ \\
User Net Surplus & $\mathrm{CS}^{*}=\frac{9}{8(2+\theta)}$ & \\
\hline
\end{tabular}

\subsection{Numerical Analysis}

In order to analyze the decision of two video sites in competition and in cooperation under operating process, we calculated the optimal decision of two sites when $\theta$ (the user experiencing difference between two sites) takes 0.1000 , $0.3000,0.5000,0.7000,0.9000$. The results are shown in Table 3 .

Table 3. Optimal Decision Results with different $\theta$

\begin{tabular}{cccccc}
\hline$\theta$ & 0.1000 & 0.3000 & 0.5000 & 0.7000 & 0.9000 \\
$p_{1}{ }^{*} / \beta$ & 0.4881 & 0.4678 & 0.4516 & 0.4394 & 0.4312 \\
$p_{1}{ }^{* *} / \beta$ & 0.4762 & 0.4348 & 0.4000 & 0.3704 & 0.3448 \\
$p_{2}{ }^{*} / \beta$ & 0.4878 & 0.4649 & 0.4435 & 0.4231 & 0.4030 \\
$p_{2}{ }^{* *} / \beta$ & 0.4762 & 0.4348 & 0.4000 & 0.3704 & 0.3448 \\
$a_{1}{ }^{*} \alpha$ & 0.2438 & 0.2313 & 0.2188 & 0.2063 & 0.1938 \\
$a_{1}{ }^{* *} \alpha$ & 0.2500 & 0.2500 & 0.2500 & 0.2500 & 0.2500 \\
$a_{2}{ }^{*} \alpha$ & 0.2439 & 0.2325 & 0.2218 & 0.2116 & 0.2015 \\
$a_{2}{ }^{* *} \alpha$ & 0.2500 & 0.2500 & 0.2500 & 0.2500 & 0.2500 \\
$\prod_{a_{1}{ }^{*} \alpha / \beta}{ }^{* *}$ & 0.0566 & 0.0465 & 0.0381 & 0.0311 & 0.0250 \\
$\prod_{1}{ }^{*} \alpha / \beta$ & 0.0595 & 0.0543 & 0.0500 & 0.0463 & 0.0431 \\
$\prod_{a^{*}}{ }^{*} \alpha / \beta$ & 0.0567 & 0.0469 & 0.0392 & 0.0327 & 0.0271 \\
$\prod_{a_{2}}{ }^{* *} \alpha / \beta$ & 0.0595 & 0.0543 & 0.0500 & 0.0463 & 0.0431 \\
$q_{1}{ }^{*}$ & 0.7202 & 0.6687 & 0.6258 & 0.5901 & 0.5604 \\
$q_{1}{ }^{* *}$ & 0.7143 & 0.6522 & 0.6000 & 0.5556 & 0.5172 \\
$q_{2}{ }^{*}$ & 0.7201 & 0.6672 & 0.6218 & 0.5819 & 0.5463 \\
$q_{2}{ }^{* *}$ & 0.7143 & 0.6522 & 0.6000 & 0.5556 & 0.5172 \\
$R_{1}{ }^{*} \alpha / \beta$ & 0.1190 & 0.1082 & 0.0988 & 0.0906 & 0.0835 \\
$R_{1}{ }^{* *} \alpha / \beta$ & 0.1190 & 0.1087 & 0.1000 & 0.0926 & 0.0862 \\
$R_{2}{ }^{*} \alpha / \beta$ & 0.9506 & 0.8549 & 0.7623 & 0.6722 & 0.5838 \\
$R_{2}{ }^{* *} \alpha / \beta$ & 0.1190 & 0.1087 & 0.1000 & 0.0926 & 0.0862 \\
$C S^{*}$ & 0.5446 & 0.5131 & 0.4864 & 0.4636 & 0.4440 \\
$C^{* * *}$ & 0.5357 & 0.4891 & 0.4500 & 0.4167 & 0.3879 \\
\hline
\end{tabular}

In order to compare the results (advertising price, advertising demand, advertisers' return, user demand, website income, user net surplus) of the two video sites before and after cooperation, we plotted the tendency chart of the ratios between variables before and after cooperation, as seen Figures 2 and 3. Because the values of the variables are positive, so, after calculating the ratio of the values of after- $/$ before-cooperation, we can tell the change after cooperation. If the ratio is greater than 1 , the values increase after cooperation; if ratio is less than 1 , the values decrease after cooperation.

Pro. 3 In operation process, no matter what value $\theta$ is, comparing cooperation with competition of two video sites, the values of advertising price, user demand and user net surplus decrease, and the values of advertising quantity, advertiser's return, website income increase.

As seen from Figure 2, no matter what value $\theta$ is, the ratios of after-/before- cooperation in advertising price, user quantity and user net surplus are less than 1. As seen from Figure 3, the ratios of after-/before- cooperation in advertising quantity, advertisers' return and website income are greater than 1. Although the advertising price is lower, lower advertising price increases the advertisers' willingness to ad on video site. Then the advertising quantity increases. So does the incomes of the advertisers and the website. Meanwhile, more ads increase user's disgust against ad. Some users leave, and then user demand decreases, which increases user net surplus of watching online video.

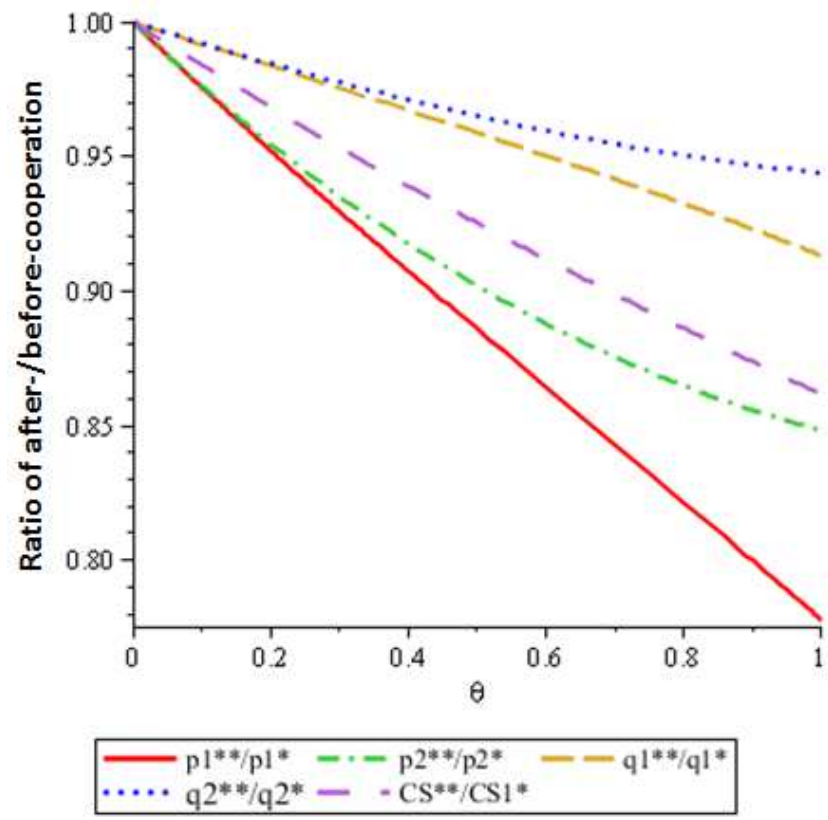

Fig. 2. Ratio of after-/before-cooperation (ration less than 1).

Pro. 4 The difference between cooperation and competition in advertising price, user demand, user net surplus, ads quantity, advertisers' profit, video sites' income is growing greater as $\theta$ increases.

The increase of $\theta$, that is, users' experience difference between two video sites increases, means the cost of user's transferring one site to another site increases. As seen from Figure 2, as $\theta$ increases, the ratios of after-/beforecooperation in advertising price, user demand and user net surplus are getting smaller. As seen from Figure 3 , as $\theta$ increases, the ratios of after-/before- cooperation in ads quantity, advertisers' revenue and video sites' income are getting greater. When $\theta=0$, there is no difference of users' 
experience between the two video sites, and the ratios in all variables are equal, i.e., there is no difference between cooperation and competition. When $\theta$ increases gradually, the difference of users' experience in two video sites is getting greater, i.e., the difference between cooperation and competition increases. When $\theta=1$, the user experience difference reaches it maximum, as well the difference between cooperation and competition. In all, the greater $\theta$ is, the greater cooperation utility is, and the two sites should take the cooperation decision.
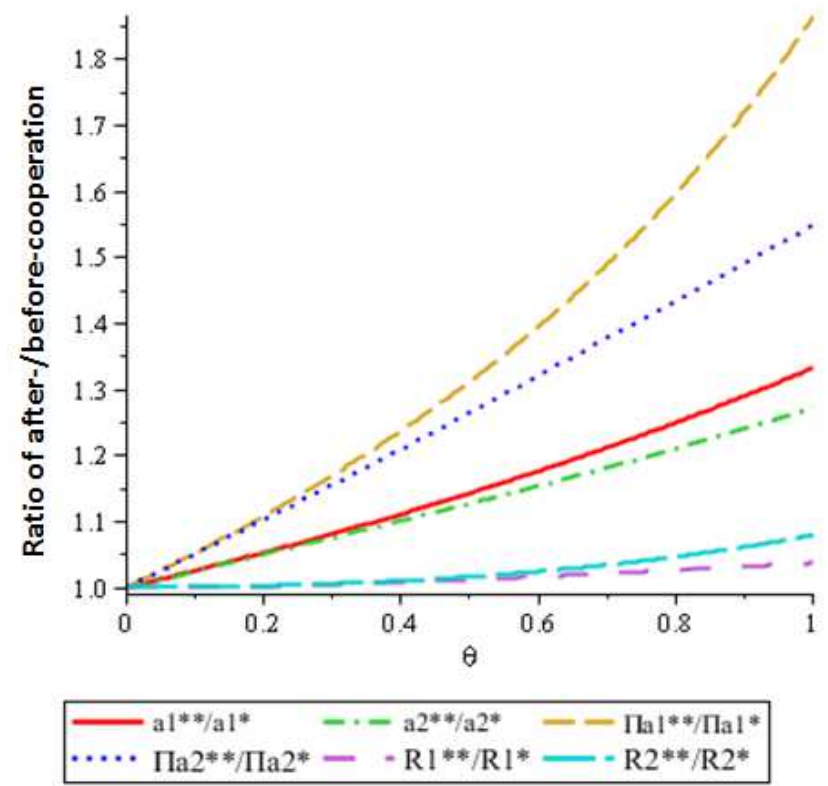

Fig. 3. Ratio of after-/before-cooperation (ration greater than 1).

\section{Conclusion}

Over the past years, online video service has been developing rapidly. Nowadays, it is still in the early stages but become the first major application of the Internet. And the online video services platform, video sites, has become the core attention of the industry. A lot of video sites are, with their own advantages on recourses and operation, competing with each other in the matter of video content, income, users' experience and others. In this paper, we comprehensively analyze the roles of video sites, copyright agent, advertisers and users, and then mainly study the cooperative and competitive relationship between different video sites.

Undoubtedly, there is a competition relationship between video sites. We build a duopoly model and use game theory to analyze the cooperation and competition relationship between two video sites during their operation and the negotiation with copyright agent. We find that comparing with competition, cooperation relationship is advantageous to purchase the video copyright and deduct the purchasing cost, also to increase each site's ads quantity and income. Therefore, we believe that working together is the best way for online video services developing in health.

Nowadays online video service is developing rapidly, and its users are lot and cover wider fields. However, its platform, video sites, gain few profit, and many sites are still at a loss. There is a statement from online video service: the video sites profit comes from the appearance of monopolization, which confirmed by this paper. In a duopoly model, two parties make an alliance then this alliance becomes the only monopoly which has a stronger pricing power and enhances their profitability. In that way we can well explain the merge of Youku and Tudou, who are two leaders in the Chinese online video market.

After this study, we believe that the online video service will get more and more attention in the academic, then the works will lead online video service to develop in a more rational and healthier way.

\section{Acknowledgement}

This research is supported by Major Program of National Science Foundation of China (Project No. 71090403/ 71090400) and Program for New Century Excellent Talents in University (NCET-11-0153) and the Twelfth Five-year Planning Project for Guangdong philosophy and social science (GD14CGL09).

\section{References}

[1] Rochet J C, Tirole J. Platform Competition in Two-sided Markets[J]. Journal of the European Economic Association, 2003, 1(4): 990-1029.

[2] Caillaud B, Jullien B. Chicken \& egg: Competition Among Intermediation Service Providers[J]. RAND Journal of Economics, 2003: 309-328.

[3] Armstrong M. Competition in Two-sided markets[J]. RAND Journal of Economics, 2006, 37(3): 668-691.

[4] Reisinger M. Platform Competition For Advertisers And Users In Media Markets[J]. International Journal of Industrial Organization, 2011, 30(2):243-252.

[5] Anderson S P, Coate S. Market Provision Of Broadcasting: A Welfare Analysis[J]. The review of Economic Studies, 2005, 72(4): 947-972.

[6] Peitz M, Valletti T M. Content and Advertising In The Media: Pay-tv Versus Free-to-air[J]. International Journal of Industrial Organization, 2008, 26(4): 949-965.

[7] Prasad A, Mahajan V, Bronnenberg B. Advertising Versus Pay-Per-View In Electronic Media[J]. International Journal of Research in Marketing, 2003, 20(1): 13-30.

[8] Choi J P. Broadcast Competition And Advertising With Free Entry: Subscription vs. Free-to-air[J]. Information Economics and Policy, 2006, 18(2): 181-196.

[9] Kaiser U, Song M. Do Media Consumers Really Dislike Advertising? An Empirical Assessment Of The Role Of Advertising In Print Media Markets[J]. International Journal of Industrial Organization, 2009, 27(2): 292-301.

[10] Kind H J, Nilssen T, Lars S Ørgard. Competition for Viewers and Advertisers in a TV Oligopoly[J]. Journal of Media Economics, 2007, 20(3): 211-233. 
[11] Häckner J, Nyberg S. Advertising and Media Market Concentration[J]. Journal of Media Economics, 2008, 21(2): 79-96.

[12] Crampes C, Haritchabalet C, Jullien B. Advertising, Competition and Entry in Media Industries[J]. The Journal of Industrial Economics, 2009, 57(1): 7-31.

[13] Gabszewicz J J, Laussel D, Sonnac N. Programming and Advertising Competition in the Broadcasting industry[J].
Journal of Economics \& Management Strategy, 2004, 13(4): 657-669.

[14] Bengtsson M, Kock S. "Coopetition" in Business Network-to Cooperate and Compete Simultaneously[J]. Industrial marketing management, 2000, 29(5): 411-426.

[15] Haaland J I, Kind H J. R\&D Policies, Trade and Process Innovation[J]. Journal of International Economics, 2008, 74(1): 170-187. 